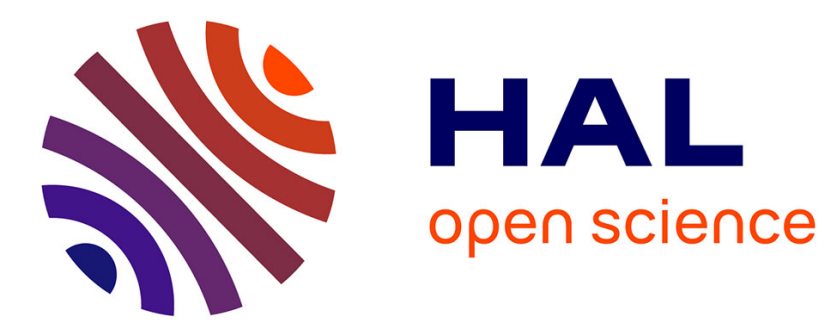

\title{
The submissive pattern of postconflict affiliation in asymmetric relationships: a test in male and sexually coerced female baboons.
}

\author{
Alice Baniel, Christine Webb, Guy Cowlishaw, Elise Huchard
}

\section{To cite this version:}

Alice Baniel, Christine Webb, Guy Cowlishaw, Elise Huchard. The submissive pattern of postconflict affiliation in asymmetric relationships: a test in male and sexually coerced female baboons.. Animal Behaviour, 2021, 175, pp.87-97. 10.1016/j.anbehav.2021.02.014 . hal-03192677

\section{HAL Id: hal-03192677 \\ https://hal.science/hal-03192677}

Submitted on 10 Jun 2021

HAL is a multi-disciplinary open access archive for the deposit and dissemination of scientific research documents, whether they are published or not. The documents may come from teaching and research institutions in France or abroad, or from public or private research centers.
L'archive ouverte pluridisciplinaire HAL, est destinée au dépôt et à la diffusion de documents scientifiques de niveau recherche, publiés ou non, émanant des établissements d'enseignement et de recherche français ou étrangers, des laboratoires publics ou privés. 
1 Published in final edited form as:

2 Animal Behaviour (2021), 175: 87-97. https://doi.org/10.1016/j.anbehav.2021.02.014

3

4 The submissive pattern of postconflict affiliation in asymmetric 5 relationships: a test in male and sexually coerced female baboons

6

7

Alice Baniel1,2,6,*, Christine E. Webb ${ }^{3,6}$, Guy Cowlishaw ${ }^{4}$, Elise Huchard ${ }^{5,7}$

8

$9 \quad{ }^{1}$ Institute for Advanced Study in Toulouse, Toulouse, France.

$10{ }^{2}$ Department of Anthropology, Stony Brook University, Stony Brook, NY, U.S.A.

113 Department of Human Evolutionary Biology, Harvard University, Cambridge, MA, U.S.A.

$12{ }^{4}$ Institute of Zoology, Zoological Society of London, London, U.K.

$13{ }^{5}$ Institute of Evolutionary Biology of Montpellier (ISEM), UMR 5554, Université de

14 Montpellier, CNRS, IRD, EPHE, Montpellier, France

$15{ }^{6}$ These authors contributed equally

$16 *$ Corresponding author.

17 E-mail: alice.baniel@gmail.com 


\section{ABSTRACT}

19 Reconciliation, or postconflict (PC) affiliation between former opponents, is a widespread conflict management strategy in animal societies, so-named for its relationship-repair function. However, another possibility is that PC affiliation reflects a submissive response of victims towards aggressors to limit conflict escalation when the power imbalance between the opponents is large. Here we investigated this hypothesis in a highly asymmetric relationship context: heterosexual wild chacma baboon, Papio ursinus, dyads involving sexually receptive females, where sexual coercion by males is common. We found several lines of support for the submissive hypothesis in the context of sexual coercion. First, rates of sexual and nonsexual PC affiliative interactions in these dyads exhibited significant and comparable increases compared to baseline conditions (ca. three-fold). Second, the baseline strength of the heterosexual social bond (outside of an aggressive context) did not predict the likelihood of sexual and nonsexual PC affiliation. Third, mate-guarded females, which could not escape the proximity of their aggressor (and faced high risks of renewed aggression), exhibited the most PC affiliation with males. Finally, most PC affiliation sequences contained at least one sexual act, and the first sexual affiliative act was primarily initiated by females via presenting. This suggests that female victims affiliate in a submissive way by displaying sexual compliance to aggressive males. Nevertheless, we cannot exclude the co-occurrence of ‘true' reconciliation: a quarter of PC affiliations between males and receptive females were exclusively nonsexual, and the first general affiliative act was equally initiated by males and females. Overall, our results suggest a mixed PC affiliation strategy in which submission may play an important role in highly asymmetric relationships and indicate the function of PC affiliation may vary from submission to reconciliation depending on the species, dyads,

41 individuals and conflicts under consideration. Future research on PC interactions would 42 usefully consider this full spectrum. 


\section{KEYWORDS}

aggression, chacma baboon, male-female association, reconciliation, sexual coercion

\section{INTRODUCTION}

Two animals are said to have reconciled if, soon after an aggressive interaction between them, they engage in friendly contact (de Waal \& van Roosmalen, 1979). Several nonexclusive hypotheses have been proposed to predict the distribution of reconciliation across opponent dyads (Arnold, Fraser, \& Aureli, 2010), with proximate or ultimate explanations emphasizing its conciliatory nature (see Table 1). Friendly reunions following conflict may serve to repair mutually beneficial (i.e. fitness-enhancing) relationships (the 'valuable relationship' hypothesis: Kappeler and van Schaik 1992; de Waal and Aureli 1997), attenuate uncertainty or anxiety (the 'uncertainty reduction' hypothesis: Aureli, 1997; Aureli \& van Schaik, 1991), or communicate peaceful intentions between former opponents (the 'benign intent' hypothesis: Silk 1996). The 'integrated' hypothesis combines the uncertainty reduction and valuable relationship hypotheses by proposing that disruptions to valuable bonds are particularly stressful for opponents, and therefore warrant stronger resolution attempts (Aureli, 1997). Although they occasionally generate different predictions, these hypotheses are generally treated as complementary, with expressions of benign intent serving to reduce uncertainty about the conflict and thereby restore valuable relationships (Aureli, Cords, \& van Schaik, 2002; Cords \& Aureli, 1996; Schaffner \& Aureli, 2004). Tests of these hypotheses have commonly focused on primates, where the frequency and patterning of reconciliation vary according to the nature of the social systems and relationships under study (Arnold et al., 2010).

Theory and research on reconciliation have previously emphasized variation in postconflict (PC) behaviour across different levels of dominance asymmetry, with more 
egalitarian species showing higher conciliatory tendencies than despotic ones (Thierry, 2000; Thierry et al., 2008). However, power imbalances have largely been considered at the level of the species or social organization rather than the dyadic level. In more hierarchical relationship contexts, two opponents may not ascribe equivalent fitness value to each other, and/or may not share equally in their uncertainty or anxiety about renewed aggression. These asymmetries highlight how the form, motive and function of PC behaviour may vary even within a dyad in ways not explicitly captured by existing reconciliation frameworks. Reflecting the full spectrum and complexity of primate social relationships, PC interactions can either be more reciprocal and conciliatory or hierarchical and coercive in nature.

One intriguing possibility is that, in the context of highly asymmetrical relationships, PC affiliation represents a submissive response by victims towards their recent aggressors (the 'submissive' hypothesis; de Waal, 1986; Kutsukake \& Clutton-Brock, 2006). In other words, rather than expressing a motivation for peaceful and friendly interactions, victims of aggression may affiliate out of fear in order to accede to aggressors' demands by displaying submission/compliance in an attempt to limit conflict escalation and injury. Several theoretical and experimental studies have emphasized the ubiquity of hidden threats and punishment in animal societies, and their role in enforcing cooperation across a range of contexts, particularly when the power imbalance between the opponents is pronounced (Cant, 2010; Clutton-Brock \& Parker, 1995a). We propose here that prolonged intimidation and repeated aggression in a given dyad with high power asymmetry may yield PC interactions that are more characteristic of a submissive rather than conciliatory scenario, even if it takes the form of a typical affiliation (e.g. grooming).

At the ultimate level, the submissive hypothesis and the uncertainty reduction hypothesis may generate similar predictions, i.e. PC affiliation functions to limit renewed 
93 three important ways. First, at the proximate level, the underlying motivations for PC

94 affiliation differ. In the uncertainty reduction hypothesis, both victims and aggressors affiliate to reduce physiological stress and anxiety about future interactions (the distress may come

96 from the damage to a valuable relationship, or because opponents live in proximity and may

97 incur future costs, for example of increased vigilance or decreased tolerance, if conflicts persist; Aureli et al., 2002). In contrast, the submissive hypothesis posits that victims submit to comply with aggressors out of fear, often conferring immediate social/sexual benefits upon aggressors. Second, the submissive hypothesis posits that victims affiliate to comply with their aggressor's demands, rather than to preserve a valuable relationship (as clarified by the integrated hypothesis). Consequently, the asymmetry of power between opponents rather than the strength of their social bond (relationship value) should predict the occurrence of PC affiliation. Third, the submissive hypothesis predicts that victims would be more likely to initiate PC affiliation, in contrast to the uncertainty reduction hypothesis, in which such distinctions are neither categorically made nor found (Arnold et al., 2010). PC interactions among heterosexual pairs have rarely been studied in wild

108 promiscuous primates but represent an ideal context in which to explore this submissive framework because of pronounced sexual dimorphism and power asymmetries between males and females. Recent work has highlighted a previously underappreciated density and

111 complexity of primate heterosexual relationships (Archie, Tung, Clark, Altmann, \& Alberts,

112 2014; Fürtbauer, Heistermann, Schülke, \& Ostner, 2014; Machanda, Gilby, \& Wrangham,

113 2013; Reddy \& Mitani, 2020). On the one hand, males and females can form enduring bonds, 114 which enhance individual survival and reproductive success (Archie et al., 2014; Campos et 115 al., 2020; Palombit, 2000). On the other hand, heterosexual relationships can be violent since 116 males commonly attack sexually receptive females to achieve mating benefits, either 117 immediately (through forced copulation or sexual harassment) or subsequently (through 
119 Thompson, \& Wrangham, 2007; Smuts \& Smuts, 1993). Sexual coercion usually targets the

120 most fertile females and can be costly in terms of stress and injury for the victims (Baniel,

121 Cowlishaw, \& Huchard, 2017; Colmenares, Polo, \& Herna, 2014; Kitchen et al., 2009;

122 Muller et al., 2007; Swedell et al., 2014). Females could thus benefit from evolving

123 behavioural strategies to decrease the chances of escalated or renewed aggression from 124 coercive males.

125 In the handful of studies that have investigated male-female PC affiliation, sexual 126 behaviours have rarely been systematically analysed. Generally, whereas noncopulatory 127 sexual behaviours (e.g. presenting and mounting) feature commonly in studies of 128 reconciliation, copulations have been omitted as a form of PC affiliation for a number of 129 potential reasons (e.g. they do not occur among same-sex dyads or they do occur but are not 130 interpreted as affiliative acts). When sociosexual contacts are incorporated, they are often 131 aggregated with other affiliative contacts, precluding formal tests between reconciliation and 132 sexual coercion (but see Call et al. 1999). To our knowledge, bonobos, Pan paniscus, are the 133 only species for which copulations and nonconceptive sexual behaviours are thought to play a 134 key role in conciliatory reunions (Clay \& de Waal, 2014; Palagi, Paoli, \& Tarli, 2004). In less tolerant animal societies where aggression is more severe and asymmetric, it is possible that

136 PC affiliations traditionally interpreted as conciliatory reunions in some cases represent

137 submissive responses to sexual (or other forms of) coercion. In particular, sexual harassment,

138 defined as repeated and costly aggressive mating attempts by males that induce females to 139 mate (Clutton-Brock \& Parker, 1995b), is operationally identified by increases in males' 140 chances of mating with their victims immediately following aggression (compared to baseline 141 chances). Thus, the conceptual frameworks supporting reconciliation and sexual harassment 142 make overlapping predictions regarding increased rates of affiliation following conflicts, 
143 provided sexual behaviours count as affiliative interactions. Yet the sexual coercion and

144 reconciliation literatures rarely reference one another.

145 In this study, we investigated the form and function of PC affiliative interactions

146 among males and sexually receptive (i.e. swollen) females in wild chacma baboons, Papio

147 ursinus. Chacma baboons live in female-bonded societies, where immigrant males fight to

148 achieve dominance and monopolize swollen females through long (i.e. several consecutive

149 days) episodes of mate guarding around ovulation (Bulger, 1993; Weingrill, Lycett, Barrett,

150 Hill, \& Henzi, 2003). This mate guarding is coercive in the sense that females cannot escape

151 male proximity, and males regularly herd their consort females away from rivals (Cheney \&

152 Seyfarth, 1977; Kitchen, Cheney, \& Seyfarth, 2005; Kitchen et al., 2009). While

153 reconciliation has been documented in this species, the focus has predominantly been on

154 female-female dyads (Cheney, Seyfarth, \& Silk, 1995; Silk, Cheney, \& Seyfarth, 1996;

155 Wittig, Crockford, Wikberg, Seyfarth, \& Cheney, 2007). Only one study has focused on PC

156 affiliation among heterosexual chacma baboon dyads, which found that reconciliation

157 commonly occurs between males and pregnant/lactating females when they are involved in a

158 'friendship', a long-term heterosexual social bond formed around an infant (Webb, Baniel,

159 Cowlishaw, \& Huchard, 2019). Little is known about patterns of PC affiliation between

160 males and swollen females. Male aggression towards swollen females is common in this

161 species, inflicting frequent injuries to females (Baniel et al., 2017; Kitchen et al., 2009), and

162 functions as a form of sexual intimidation, where repeated aggression throughout the cycle

163 increases the aggressor's chances of consorting with the female around ovulation (Baniel et

164 al., 2017). There is, however, no evidence for sexual harassment, where males harass females

165 until they accept matings, as there is no immediate increase in the rate of mating following

166 male aggression (Baniel et al., 2017). On a spectrum ranging from submission to

167 reconciliation, affiliation following conflicts between males and swollen females in this 
coercive context may fall closer to the former. In this case, female victims would adopt a compliant strategy to reduce the costs of conflict escalation (e.g. injury), while male aggressors enact a coercive strategy to secure immediate or future mating opportunities

\section{1 (Table 1).}

Here, we tested whether the pattern of PC affiliation between heterosexual pairs

173 involving sexually receptive females could be explained by the submission hypothesis in the context of sexual coercion, via the following four predictions. First, we predicted that increases in PC affiliation between males and swollen females would involve both sexual and nonsexual affiliation (Prediction 1, P1), as intimidated females may use any behavioural

177 strategy at their disposal, for example sexual solicitations or grooming, to appease coercive 178 males. Second, we predicted that the rate of PC affiliation between a male and swollen 179 female would not reflect the strength of their social bond in baseline conditions (i.e. outside an aggressive context; P2). Third, we predicted that the rate of PC affiliation would increase in more coercive contexts; namely, mate-guarded females should display a higher rate of PC

182 affiliation than unguarded females, because they cannot escape the spatial proximity of their 183 aggressor and thus have a higher incentive to de-escalate conflicts with him (P3). Lastly, we predicted asymmetrical patterns in who initiates PC affiliation, particularly when it comes to sexual affiliations, where females should be mostly responsible for initiating the first affiliative act (P4a) and/or the first sexual act of the PC affiliation sequence (P4b) in order to

187 display submission and propose positive sociosexual contacts to coercive males following aggression.

This predictive framework differentiates itself from that generated by previous hypotheses to explain pos-conflict affiliation, including both the sexual harassment

191 hypothesis, and the integrated hypothesis. According to the former, if patterns of affiliation 192 solely reflected sexual harassment, we would expect no support for P1 (rather, we would 
193 expect only sexual PC affiliation to increase) or P4 (we would expect males rather than

194 females to initiate copulations). According to the latter, if patterns of affiliation solely

195 reflected attempt to reduce anxiety and repair a valuable bond, we would expect no support

196 for P2 or P3 (because we would expect baseline affiliation rather than the power asymmetry

197 between opponents to predict PC affiliation).

198

199 METHODS

200 Data Collection

201 We studied two habituated groups of wild chacma baboons living at Tsaobis Nature Park, a 202 semiarid environment in Namibia (Cowlishaw, 1997) over four field seasons (2005, 2006, 2032013 and 2014) of variable length (5-9 months per year). Groups contained 3-11 adult males and 9-19 adult females according to the period of study. Dominance ranks of adult males and females were established using both ad libitum and focal observations of dyadic agonistic interactions (see Appendix 1)

The reproductive state of each adult female was monitored daily and categorized as pregnant, lactating, cycling swollen (i.e. sexually receptive with a perineal swelling) and cycling nonswollen (i.e. between two swelling phases). Mate-guarding episodes, defined as periods when swollen females were constantly followed by a male that mated exclusively with them and prevented others from doing so (Alberts, Altmann, \& Wilson, 1996), were

212 monitored ad libitum daily, and confirmed or updated accordingly for each focal observation.

213 In the following analyses, we focused only on cycling swollen females and their interactions with adult males.

Observers followed groups on foot daily from dawn to dusk, conducting $1 \mathrm{~h}$ focal 216 observations on all adult females and males, spread equally across the day. In total, we 217 collected 1418 focal observations on 40 swollen females (mean \pm SD: $35.5 \pm 32.2$ observations 
218 per individual) and 524 observations on 25 males (21.0 \pm 8.8 ; male focal observations were

219 only collected in 2013-2014). During observations, we continuously recorded all occurrences

220 of male-female agonistic and affiliative interactions involving the focal individual, including

221 the partner's identity and the direction of the interaction. Agonistic interactions comprised

222 attacks (any aggressive physical contact), chases and physical threats (including staring, head

223 bobbing and ground sweeping while oriented towards the targeted individual) and approach-

224 avoid interactions (supplants, displacements). For the analysis of PC affiliation, we only used

225 attacks, chases and physical threats because more subtle agonistic interactions such as

226 displacements, supplants or vocal threats are less likely to be stressful for the victim. As

227 expected on the basis of pronounced sexual dimorphism, 98\% of aggression between males

228 and swollen females (i.e. 92 of 94 observed conflicts) were directed from males to females.

229 Affiliative interactions included grunts, positive facial expressions (come-here faces, lip-

230 smacks, sniff-mouths), positive physical contacts (touching, embracing, grooming, sniffing or

231 touching perineum, mounting, grasping pelvis) and sexual behaviour (presents, copulations).

232 Note that swollen females in this species invite males to copulate by presenting, which can

233 potentially directly lead to sex. A female's presenting behaviour can be either followed by a

234 copulation (in which case, observers only noted the copulation and indicated that the

235 copulatory act was female initiated) or not followed by a copulation when the male ignores

236 the female's initiative (in which case, observers only recorded the presenting bout). For each

237 copulation, we thus recorded whether it was initiated by the female (via presenting) or by the

238 male (by approaching and usually grabbing the female's hindquarters).

239

240 Statistical Analyses

241 Rate of sexual and nonsexual PC affiliation 
242 We first tested whether swollen females and males exhibit higher rates of affiliation

243 following male aggression (compared to baseline conditions), and whether any increase

244 detected in PC affiliation is primarily attributable to increases in sexual versus nonsexual

245 behaviours (P1). Using the collected focal observations of males and swollen females, and

246 following a statistical methodology previously validated in our study system (Webb et al.,

247 2019), we established the rate of (1) sexual affiliation (presenting and copulations) and (2)

248 nonsexual affiliation (e.g. grunts, grooming, etc) between a given heterosexual dyad

249 immediately after a conflict (i.e. the PC sexual and nonsexual affiliation rate) versus in the

250 absence of an immediate conflict (i.e. the baseline sexual and nonsexual affiliation rate).

251 Specifically, for each heterosexual dyad that exchanged at least one act of aggression, we

252 first identified all focal observations that were conducted on both individuals in a given year

253 and in which the female was swollen. Then, we split these observations into two categories.

254 First, the PC sample, in which we pooled all 15 min observations following a conflict

255 between the same dyad together (i.e. dyads had between one to five conflicts, each of which

256 generated a 15 min observation period, so we pooled the corresponding 15-75 min of PC

257 observation to calculate the rate of PC affiliation of a given dyad). We chose a duration of 15

258 min following each conflict because our validation study identified this time window as the

259 best trade-off between the number of available PC observations (which decreases as time

260 period increases) and the strength of the reconciliation signal (which increases as time period

261 increases; Webb et al., 2019). Incomplete PC observations (e.g. due to the focal individual

262 going out of sight or the occurrence of another bout of aggression shortly after the first one)

263 were retained only if they lasted for at least 9 min without interruption (mean $\pm \mathrm{SD}=12.1 \pm 1.6$

264 min, $N=15$ incomplete PC of 94 total PC observations). This 9 min threshold was chosen

265 because the mean latency between aggression and the first affiliative act was $4.5 \pm 4.2 \mathrm{~min}$

266 (calculated over 37 occurrences of PC affiliation in complete PC observations). We thus 
considered that 9 min would be enough time to capture, in most cases, the potential occurrence of PC affiliation acts.

Second, for the baseline sample, we pooled the rest of the focal observations of the dyad. To establish these baseline rates, we excluded each 15 min period following a conflict (i.e. the PC samples), as well as each 15 min period at the start of the focal observation or following its resumption after the focal individual briefly went out of sight (if an aggression occurred between the two members of the dyad when they were not visible). Third, we tabulated the number of times that the two individuals affiliated sexually or nonsexually in the PC and baseline samples, respectively, as well as the total observation time of the corresponding (i.e. PC or baseline) sample.

We compared the strength of the PC affiliation signal between males and swollen females when considering only sexual affiliations versus only nonsexual affiliations. We thus ran two negative binomial generalized linear mixed models (GLMMs) using the total number of affiliations exchanged between each male and swollen female dyad as the response variable and including (1) only sexual affiliations or (2) only nonsexual affiliations in the count. Fixed effects comprised the type of observation (PC versus baseline samples) and the dominance ranks of the female and male. The total observation time of the corresponding sample (PC or baseline) was log transformed and included as an offset variable. Random effects comprised the identity of the female and male.

\section{Determinants of the occurrence of PC affiliation}

We then investigated the determinants of the presence (versus absence) of PC affiliation in the subsequent 15 min following aggression ( $N=94$ PC observations), namely with respect to the strength of the affiliative relationship of the dyad in baseline conditions (i.e. outside an aggressive context, P2) and female mate-guarding status (P3). We ran a binomial GLMM 
292 using the occurrence of affiliation following an aggressive event (yes/no) as the response 293 variable. Fixed effects comprised the mate-guarding status of the swollen female (unguarded

294 versus mate-guarded by the aggressor), the dyad's baseline affiliation rate (calculated via the 295 occurrence of sexual and nonsexual behaviours in swollen periods), female rank, male rank 296 and the type of aggression (chase, attack, threat). For both models, random effects comprised 297 the identities of the female and male. As supplementary analysis, we also calculated the 298 dyad's baseline affiliation rate using focal observations where the female was nonswollen 299 only.

\section{Pattern of initiation of PC affiliation}

302 We tested for asymmetry in the pattern of initiation of the first PC affiliative act (P4a) and of the first sexual act of a PC sequence (P4b) between male and female opponents using twotailed exact binomial tests.

All GLMMs were run using the glmer function of the lme4 package (Bates, Maechler, Bolker, \& Walker, 2014) in R version 3.5.2 (R Core Team, 2018). The significance of the fixed factors was tested using a likelihood ratio test, LRT (assuming an asymptotic chi-square distribution of the test statistic) via the drop1 function. We further computed the $95 \%$ parametric bootstrap confidence intervals of fixed factors (using confint.merMod) and

311 checked that they did not cross zero. To validate models, we examined the distribution of

312 residuals and confirmed the absence of overdispersion by using the DHARMa package 313 (Hartig, 2018). Sample size is indicated for each model in the relevant output table.

\section{Ethical Note}


316 This study was strictly observational and relied on behavioural data collected noninvasively

317 on animals well habituated to human observers. Our research procedures were evaluated and

318 approved by the Ethics Committee of the Zoological Society of London and the Ministry of

319 Environment and Tourism (MET), Namibia, and adhered to the ASAB/ABS Guidelines for

320 the Treatment of Animals in Behavioural Research and Teaching. Our research was

321 conducted under MET permit numbers 886/2005, 1039/2006, 1786/2013 and 1892/2014.

\section{RESULTS}

\section{Rate of sexual and nonsexual PC affiliation}

325 We observed 94 incidents of male aggression towards swollen females. Of these, 73 had a

326 documented context (as inferred by the observer): $42 \%$ were unprovoked (no apparent reason

327 for the male to attack the female), $25 \%$ were apparently triggered by the female leaving the male's spatial proximity and may represent herding, $15 \%$ involved redirected aggression to the female following aggression received from a rival male, $10 \%$ occurred during feeding

330 bouts and 7\% occurred during intragroup male display (wahoo bouts) or intergroup

331 interactions. Of these 94 observed agonistic interactions, $43(46 \%)$ were followed by at least one affiliative act between the male and swollen female in the following $15 \mathrm{~min}$. The latency before the first affiliative act was $4.7 \pm 4.2 \mathrm{~min}$ on average (range $0-13 \mathrm{~min}$ ). As expected under P1, the observed rates of affiliation between males and swollen females following conflicts were significantly higher (about three times more) than in baseline samples when

336 considering exclusively sexual behaviours (mean rate of affiliation \pm SD in PC: $0.033 \pm 0.054$ events/min; in baseline: $0.010 \pm 0.011$; Table 2, Fig. 1a). The same was true when considering exclusively nonsexual behaviours (mean rate of affiliation \pm SD in PC: $0.044 \pm 0.069$ events/min; in baseline: $0.013 \pm 0.017$; Table 2, Fig. 1a). Females were more likely to exhibit 
sexual affiliations (but not more nonsexual affiliations) with high-ranking males in both PC and baseline conditions.

\section{Determinants of the occurrence of PC affiliation}

344 Heterosexual dyads with strong affiliative relationships in baseline conditions were not more

345 likely to display affiliation following aggression (Table 3, Appendix 2, Table A1), consistent with P2. Nevertheless, there was a high uncertainty around this effect, with a lot of variation across dyads (Appendix 2, Fig. A1). According to P3, higher rates of PC affiliation are expected when females are confined in close proximity to mate-guarding males. The need for PC affiliation under these circumstances is highlighted by the finding that 38 of 41 recorded incidences of male aggression towards mate-guarded females came directly from their consort male. As predicted, males and swollen females involved in a mate-guarding consortship were more likely to exhibit PC affiliation than when they were not involved in a consortship (Table 3, Fig. 1b).

\section{Pattern of initiation of PC affiliation}

When PC affiliation occurred ( $N=43$ cases), $32(74 \%)$ cases involved at least one sexual behaviour and $11(26 \%)$ involved exclusively nonsexual behaviours in the 15 min sequence following aggression. Among these 43 PC sequences, the first PC affiliative act was initiated equally by males and females, contrary to P4a: males initiated $23 \mathrm{PC}$ affiliations and females

360 initiated $20 \mathrm{PC}$ affiliations (two-tailed exact binomial test: $P=0.761 ; 95 \%$ confidence interval: 0.31-0.62; see Fig. 2a and Appendix 2, Table A2 for behavioural details on the first affiliative act). However, when focusing on those 30 PC affiliations that contained at least one sexual act (two sexual interactions had unknown initiators), the first sexual behaviour was initiated 21 times by the female, mostly via presenting, and nine times by the male, in 
accordance with $\mathrm{P} 4 \mathrm{~b}$ (two-tailed exact binomial test: $P=0.043 ; 95 \%$ confidence interval: 0.51-0.85; Appendix 2, Table A2, Fig. 2b). In the $11 \mathrm{PC}$ affiliations that remained exclusively nonsexual, three were initiated by females and eight by males.

\section{DISCUSSION}

370 The present study reveals that in highly asymmetrical relationship context, like those characterizing heterosexual dyads in chacma baboons, PC affiliation may frequently correspond to a submissive response from victims to a powerful opponent, rather than reflecting a conciliatory pattern. The evidence for submission by sexually receptive females to aggressive males in chacma baboons in response to sexual coercion is fourfold. First, the frequency of sexual interactions increased three-fold following aggression, just like the frequency of nonsexual affiliation (compared to baseline conditions). Second, the baseline strength of the heterosexual social bond (i.e. the 'value' of their relationship) did not predict the likelihood of PC affiliation. Third, dyads involving males and mate-guarded females, who faced high risks of renewed aggression due to the permanent proximity of their aggressor, exhibited the highest rates of PC affiliation. Finally, most PC affiliation sequences (74\%) contained at least one sexual act, and the first sexual affiliative act was primarily initiated by females via presenting. This suggests that receptive female victims often affiliate in a submissive way by displaying sexual compliance (i.e. proposing matings) to coercive males to limit the chances of escalated aggression.

PC Affiliation Reflects Female Submission to Male Intimidation

387 The observed pattern of PC affiliation between male and female baboons does not reflect a strict sexual harassment strategy, where males attack or persistently run after females until they accept mating, as reported in some ungulates (Clutton-Brock \& Parker, 1995b) and 
orangutans (Fox, 2002; Knott, 2009). Indeed, male baboons seldom initiated copulations

391 following aggression (male-initiated copulations only represented $18 \%$ of the first affiliative

392 act and $30 \%$ of the first sexual act; see Appendix 2, Table A2). Instead, females were mostly

393 responsible for initiating PC sexual behaviour by presenting to the male. Furthermore, the

394 observed increases in rates of nonsexual affiliation following conflicts were not expected

395 under the sexual harassment hypothesis, which exclusively focuses on sexual behaviour.

The fact that female baboons are primarily responsible for initiating the first sexual act following aggression is more compatible with a scenario of long-term sexual intimidation, where females would express sexual compliance towards males to appease them and limit escalated aggression and future injuries. Males, on the other hand, may rarely pursue immediate mating opportunities following aggression (and female presenting) to avoid unnecessary matings, especially when the female is not in her ovulatory window (which can be costly, e.g. sperm depletion; Gesquiere, Wango, Alberts, \& Altmann, 2007; Moscovice et al., 2010; Weingrill, Lycett, \& Henzi, 2000). Instead, they seem to use repeated aggressive and affiliative behaviour to optimize their control of female spatial behaviour. In our population, $42 \%$ of male attacks towards swollen females are unprovoked, sudden and probably unpredictable. Such randomly timed attacks provide an effective means for the aggressor to generate continuous anxiety, vigilance and chronic stress in his victims (Silk, 2002). In line with this, half of our observed PC affiliation events happened in the context of mate guarding, where females have no choice but to stay in the proximity of their aggressor

410 and are thus likely to face renewed aggression. Mate-guarding episodes are particularly long 411 in chacma baboons (between 0.5 and 32 days, mean=9 days), and can last several consecutive 412 cycles (Baniel, Cowlishaw, \& Huchard, 2016). Females might particularly benefit from 413 displaying their compliance in this context. Similar long-term sexual intimidation strategies 414 are also thought to occur in some chimpanzee, Pan troglodytes, populations: males that are 
415 repeatedly aggressive towards particular females are more likely to mate with them during

416 ovulatory periods and more likely to sire their offspring (Feldblum et al., 2014; Muller,

417 Emery Thompson, Kahlenberg, \& Wrangham, 2011; Muller et al., 2007; Muller, Kahlenberg, 418 \& Wrangham, 2009).

419 The patterns of subordination observed in female chacma baboons immediately 420 following male aggression also resemble those seen in hamadryas baboons, Papio 421 hamadryas, where males use frequent aggression to enforce the spatial proximity of females that are newly incorporated into their harem. New females spend more time affiliating with their leader male than do resident females, and in particular groom him following aggression 424 (Swedell, 2015; Swedell \& Schreier, 2009). In the long term, the aggression they face from 425 him decreases once their social bond is established and when females are 'conditioned' (or 426 'abducted') to follow their leader male (Polo \& Colmenares, 2012; Swedell, 2015; Swedell \& Schreier, 2009). Male aggression therefore specifically targets females that are weakly bonded to the aggressor, presumably to dissuade them from dispersing or leaving male proximity. The conditioning of female hamadryas baboons is probably similar to the pattern

430 we report in chacma baboons, particularly for consorting partners, where males may seek to condition their female consorts to stay in proximity. It would be interesting to test whether male aggression towards female chacma baboons decreases once the mate-guarding episode is well established and as females become more compliant (the same hetrosexual dyad often

434 consort during the receptive phase across several consecutive cycles), and whether females' 435 propensity to propose sex following aggression decreases the chances of renewed aggression 436 or conflict escalation. 
439 The observed pattern of affiliation is not fully compatible with true conciliatory tendencies, 440 under which we would expect an effect of relationship quality (i.e. baseline rates of 441 affiliation) between the two opponents on the probability of PC affiliation. In addition, we 442 would not expect any effect of mate-garding episodes on the probability of PC affiliation. 443 However, we cannot exclude the occasional occurrence of 'true' reconciliation, alongside 444 submission. Specifically, 26\% of affiliations following conflicts between males and sexually 445 receptive females were exclusively nonsexual, with nonsexual affiliative behaviours occurring three times more frequently than expected in baseline contexts, and symmetry in initiation patterns (of the first general affiliative act) suggesting that males and females were equally motivated to reconcile. It is noteworthy that had we only tested for a reconciliation signal, following the conventions of the reconciliation literature, we would have interpreted these findings as evidence of a conciliatory tendency.

A subset of PC interactions may thus be conciliatory, an interpretation reinforced by the existence of true reconciliation between new mothers and their male friends in the same population (Webb et al., 2019), as well as among female-female dyads in this species 454 (Cheney et al., 1995; Silk et al., 1996; Wittig et al., 2007). This may also explain the observed trend in the effect of baseline affiliation rates on rates of PC affiliation (Appendix 2, Fig. A1), which may reflect this minority of conciliatory PC affiliation. We might expect the occasional occurrence of reconciliation between swollen females and males on the basis that a given male and cycling female dyad occasionally maintains a preferential relationship (in terms of grooming or proximity) that may last across consecutive female cycles (Baniel et al., 2016) and that may become a friendship when they conceive an offspring together, therefore affording fitness benefits to both partners (Archie et al., 2014; Cheney, Silk, \& Seyfarth, 2012). For a swollen female, reconciling with males may further enable immediate benefits such as spatial association and tolerance, access to better food patches, and provide a buffer 
against other aggressive groupmates. For males, reconciliation may encourage swollen females to tolerate their proximity and therefore minimize the risk of extrapair matings or the loss of mate guarding to rivals (Bercovitch, 1995; Smuts, 1985).

Sex under Coercion or Affiliative 'Make-up' Sex?

469 The mixed function of PC affiliation observed in this study, encompassing both submissive and true conciliatory behaviour, raises an interesting possibility: that when female chacma baboons mate with males following aggression, this may occasionally reflect a voluntary choice of females to use sex to reconcile with males, rather than the submissive acceptance of the sexual advances of males under coercion. In bonobos, sociosexual behaviours also occur in socially tensed situations, and although their tension alleviation function remains unclear 475 (Hohmann, Mundry, \& Deschner, 2009) such sexual interactions in PC contexts are conventionally considered friendly and conciliatory ('make-up sex') (Clay \& de Waal, 2014; de Waal, 1987; Palagi et al., 2004). Importantly, however, these interactions predominantly occur in the context of female-female bonds and have a variety of documented nonconceptive functions (Hohmann \& Fruth, 2000).

While female chacma baboons may occasionally choose to use sexual affiliations to reconcile, such voluntary choice probably does not reflect the general pattern in our population, where sexual affiliations are more likely to reflect sexual appeasement under duress given the support we found for the submissive hypothesis. So overall, although sexual PC affiliation behaviour may appear similar in baboons and bonobos, the motivational and emotional basis of PC affiliation probably differs for the initiator in most cases: whereas female baboons may generally sexually submit out of fear, female bonobos may use sexual contacts in a more symmetric way, although observations suggest that such contacts are not necessarily always consensual (Z. Clay and M. Surbeck, personal communication). 
Interpretations concerning both ultimate functions and proximate motivations for PC behaviours should thus reflect the broader social dynamics of a given social system (such as power asymmetries between males and females).

\section{Wider Implications for the Reconciliation Literature}

494 The idea that PC affiliative behaviour, whether sexual or not, serves a submissive function contrasts with previous hypotheses, which generally revolve around conciliatory explanations (see Table 1; Aureli \& van Schaik, 1991; Kappeler \& van Schaik, 1992; Silk, 1996). The uncertainty reduction and integrated hypotheses emphasize the symmetric function of PC affiliation to alleviate anxiety and restore a damaged, reciprocal and mutually beneficial bond, whereas the submission hypothesis highlights its asymmetry in dyads characterized by pronounced power imbalances. While the reconciliation literature has occasionally alluded to the submissive pattern of reconciliation (de Waal, 1986; Kutsukake \& Clutton-Brock, 2006), our study is the first to formally test its predictions and emphasize the full spectrum of possible PC patterns. In this study, we tested the submissive hypothesis in the specific context of coercive relationships between males and fertile female baboons, but it may apply to any kind of asymmetric relationships, which are ubiquitous in animal societies. By (re)framing the study of PC behaviour in the context of hierarchical relationships, the submissive hypothesis generates unique predictions from existing reconciliatory frameworks but does not exclude other hypotheses previously proposed to explain the occurrence of PC affiliation; such hypotheses are complementary, rather than mutually exclusive, within a given species or even dyad.

Taken together, our results emphasize the diversity of relationships possible within

512 and across dyads, where the function of PC affiliation may vary from reconciliation to 513 submission depending on the context and quality of the social bond. Attempts to separate 
these two hypotheses at the species level may be oversimplistic given the sophistication of social strategies and the individualized nature of social bonds within primate groups (Cheney \& Seyfarth, 2007; Smuts \& Smuts, 1993).

\section{Conclusion}

519 Primate societies are a mosaic of social bonds, ranging from the most coercive/hierarchical to 520 the most egalitarian/reciprocal in nature (de Waal, 1986). Conflict resolution patterns reflect 521 this spectrum, with a higher frequency of PC affiliation in more tolerant species compared to 522 more despotic ones (Thierry, 2000; Thierry et al., 2008). Our results further suggest that, on 523 top of its frequency, the very function of PC affiliation similarly varies across and within 524 populations, and hypotheses pertaining to proximate and ultimate explanations for the observed behavioural patterns should account for such variation. On the egalitarian end of the spectrum, reconciliation may be required after conflicts to restore the relationship to baseline levels of tolerance and affiliation. On the hierarchical end, reconciliation may facilitate the avoidance of injury through submissive behaviour rather than repairing social bonds. Overall,

529 a more balanced view of the functions of PC affiliation is warranted. Animal social 530 relationships are multifaceted and involve a mixture of coercive and sociopositive 531 interactions, a reality that research on PC behaviour should reflect.

\section{Author Contributions}

534 A.B., C.E.W. and E.H. designed the study and performed the analyses. A.B and E.H collected the data. All authors contributed to drafting the manuscript.

\section{Data Availability}


538 The data sets necessary to run the analyses included in this paper have been deposited in the public depository GitHub at https://github.com/AliceBaniel/The-Submissive-hypothesis.

\section{Declaration of Interest}

542 We have no competing interests.

543

\section{Acknowledgments}

545 We are very grateful to the Tsaobis Baboon Project volunteers (2005-2006 and 2013-2014)

546 for help with data collection, the Tsaobis beneficiaries for permission to work at Tsaobis, the

547 Gobabeb Research and Training Centre for affiliation, and the Snyman and Wittreich families

548 for permission to work on their land. This paper is a publication of the ZSL Institute of 549 Zoology's Tsaobis Baboon Project. Contribution ISEM 2020-339. A.B. was supported by 550 the Agence Nationale de la Recherche Labex IAST and C.E.W was supported by a Fyssen 551 Foundation postdoctoral fellowship.

\section{REFERENCES}

Alberts, S. C., Altmann, J., \& Wilson, M. L. (1996). Mate guarding constrains foraging activity of male baboons. Animal Behaviour, 51(6), 1269-1277. Archie, E. A., Tung, J., Clark, M., Altmann, J., \& Alberts, S. C. (2014). Social affiliation matters : both samesex and opposite-sex relationships predict survival in wild female baboons. Proceedings of the Royal Society B: Biological Sciences, 281(1793), 20141261.

Albers, P. C. H., \& de Vries, H. (2001). Elo-rating as a tool in the sequential estimation of dominance strengths. Animal Behaviour, 61(2), 489-495.

562 Arnold, K., Fraser, O. N., \& Aureli, F. (2010). Postconflict reconciliation. In C. J. Campbell, 

Perspective (pp. 608-625). Oxford, U.K.: Oxford University Press.

565

Aureli, F. (1997). Post-conflict anxiety in nonhuman primates: The mediating role of emotion in conflict resolution. Aggressive Behavior, 23(5), 315-328.

Aureli, F., Cords, M., \& van Schaik, C. P. (2002). Conflict resolution following aggression in gregarious animals: A predictive framework. Animal Behaviour, 64(3), 325-343.

Aureli, F., \& van Schaik, C. P. (1991). Post-conflict behaviour in long-tailed macaques (Macaca fascicularis): II. Coping with the uncertainty. Ethology, 89(2), 101-114.

Baniel, A., Cowlishaw, G., \& Huchard, E. (2017). Male violence and sexual intimidation in a wild primate society. Current Biology, 27(14), 2163-2168

Baniel, A., Cowlishaw, G., \& Huchard, E. (2016). Stability and strength of male-female associations in a promiscuous primate society. Behavioral Ecology and Sociobiology, $70(5), 761-775$.

Bates, D., Maechler, M., Bolker, B., \& Walker, S. (2014). lme4: linear mixed-effects models using Eigen and S4. R package version 1.1-7. R Package Version 1.1-7. http://cran.rproject.org/package=lme 4 .

Bercovitch, F. B. (1995). Female cooperation, consortship maintenance, and male mating success in savanna baboons. Animal Behaviour, 50, 137-149.

Bulger, J. B. (1993). Dominance rank and access to estrous females in male savanna baboons. Behaviour, 127, 67-103.

Call, J., Aureli, F., \& de Waal, F. B. M. (1999). Reconciliation patterns among stumptailed macaques: A multivariate approach. Animal Behaviour, 58(1), 165-172.

Campos, F. A., Villavicencio, F., Archie, E. A., Colchero, F., Alberts, S. C., \& Alberts, S. C. (2020). Social bonds, social status and survival in wild baboons: a tale of two sexes. Philosophical Transactions of the Royal Society B, 375, 20190621. 
Cant, M. A. (2010). The role of threats in animal cooperation. Proceedings of the Royal Society B: Biological Sciences, 278(1703), 170-178.

Cheney, D. L., \& Seyfarth, R. M. (1977). Behavior of adult and immature male baboons during intergroup encounters. Nature, 269, 404-406.

Cheney, D. L., \& Seyfarth, R. M. (2007). Baboon metaphysics-The evolution of a social mind. Chicago, IL: The University of Chicago Press.

Cheney, D. L., Seyfarth, R. M., \& Silk, J. B. (1995). The role of grunts in reconciling opponents and facilitating interactions among adult female baboons. Animal Behaviour, $50,249-257$.

Cheney, D. L., Silk, J. B., \& Seyfarth, R. M. (2012). Evidence for intrasexual selection in wild female baboons. Animal Behaviour, 84, 21-27.

Clay, Z., \& de Waal, F. B. M. (2014). Sex and strife: Post-conflict sexual contacts in bonobos. Behaviour, 152, 313-334.

Clutton-Brock, T. H., \& Parker, G. A. (1995a). Punishment in animal societies. Nature, 373, $209-216$.

Clutton-Brock, T. H., \& Parker, G. A. (1995b). Sexual coercion in animal societies. Animal Behaviour, 49, 1345-1365.

Colmenares, F., Polo, P., \& Herna, V. (2014). Male takeovers are reproductively costly to females in hamadryas baboons: A test of the sexual coercion hypothesis. PLoS One, 9(3), e90996.

Cords, M., \& Aureli, F. (1996). Reasons for reconciling. Evolutionary Anthropology, 2(5), $42-45$.

Cowlishaw, G. (1997). Refuge use and predation risk in a desert baboon population. Animal Behaviour, 54(2), 241-253.

de Waal, F. B. M. (1986). The integration of dominance and social bonding in primates. The 
614 de Waal, F. B. M. (1987). Tension regulation and non-reproductive functions of sex in 615 captive bonobos. National Geographic Research, 3, 318-335.

616 de Waal, F. B. M., \& Aureli, F. (1997). Conflict resolution and distress alleviation in 617 monkeys and apes. In C. S. Carter, B. Kirkpatric, \& I. Lenderhendler (Eds.), The 618 Integrative Neurobiology of Affiliation (Vol. 807, pp. 317-328). New York: Annals of 619 the New York Academy of Sciences.

620 de Waal, F., \& van Roosmalen, A. (1979). Reconciliation and consolation among $621 \quad$ chimpanzees. Behavioral Ecology and Sociobiology, 5(1), 55-66.

622 Feldblum, J. T., Wroblewski, E. E., Rudicell, R. S., Hahn, B. H., Paiva, T., CetinkayaRundel, M., Pusey, A.E., Gilby, I. C. (2014). Sexually coercive male chimpanzees sire more offspring. Current Biology, 24(23), 2855-2860.

Fox, E. A. (2002). Female tactics to reduce sexual harassment in the Sumatran orangutan (Pongo pygmaeus abelii). Behavioral Ecology and Sociobiology, 52(2), 93-101.

Fürtbauer, I., Heistermann, M., Schülke, O., \& Ostner, J. (2014). Low female stress hormone levels are predicted by same- or opposite-sex sociality depending on season in wild Assamese macaques. Psychoneuroendocrinology, 48, 19-28.

630

Gesquiere, L. R., Wango, E. O., Alberts, S., \& Altmann, J. (2007). Mechanisms of sexual selection: sexual swellings and estrogen concentrations as fertility indicators and cues for male consort decisions in wild baboons. Hormones and Behavior, 51, 114-125.

Hartig, F. (2018). DHARMa: Residual Diagnostics for Hierarchical (Multi-Level / Mixed) Regression Models. R package version 0.2.0. https://CRAN.Rproject.org/package=DHARMa.

636 Hohmann, G., \& Fruth, B. (2000). Use and function of genital contacts among female bonobos. Animal Behaviour, 60(1), 107-120. 
638 Hohmann, G., Mundry, R., \& Deschner, T. (2009). The relationship between socio-sexual 639 behavior and salivary cortisol in bonobos: Tests of the tension regulation hypothesis. $640 \quad$ American Journal of Primatology, 71(3), 223-232.

641 Kappeler, P. M., \& van Schaik, C. P. (1992). Methodological and evolutionary aspects of 642 reconciliation among primates. Ethology, 92(2), 51-69.

643 Kitchen, D. M., Beehner, J. C., Bergman, T. J., Cheney, D. L., Crockford, C., Engh, A. L., 644 Fischer, J., Seyfart, R.M.,Wittig, R. M. (2009). The causes and consequences of male 645 aggression directed at female chacma baboons. In M N Muller \& R. W. Wrangham (Eds.), Sexual coercion in primates and humans: an evolutionary perspective on male aggression against females (pp. 128-156). Cambridge, MA: Harvard University Press.

648 Kitchen, D. M., Cheney, D. L., \& Seyfarth, R. M. (2005). Contextual factors meditating contests between male chacma baboons in Botswana: effects of food, friends and females. International Journal of Primatology, 26(1), 105-125.

Knott, C. D. (2009). Orangutans: sexual coercion without sexual violence. In M N Muller \& 652 R. W. Wrangham (Eds.), Sexual coercion in primates and humans: an evolutionary

Kutsukake, N., \& Clutton-Brock, T. H. (2006). Aggression and submission reflect 656 reproductive conflict between females in cooperatively breeding meerkats Suricata

Machanda, Z. P., Gilby, I. C., \& Wrangham, R. W. (2013). Male-female association patterns 659 among free-ranging chimpanzees (Pan troglodytes schweinfurthii). International Cheney, D. L. (2010). Hedging their bets? Male and female chacma baboons form 

friendships based on likelihood of paternity. Animal Behaviour, 79, 1007-1015.

664

665

666

667

668

669

670

671

672

673

674

675

676

677

678

679

680

681

682

683

684

685

686

687

Muller, M. N, Kahlenberg, S. M., Emery Thompson, M., \& Wrangham, R. W. (2007). Male coercion and the costs of promiscuous mating for female chimpanzees. Proceedings of the Royal Society B: Biological Sciences, 274(1612), 1009-1014.

Muller, M. N., Emery Thompson, M., Kahlenberg, S., \& Wrangham, R. (2011). Sexual coercion by male chimpanzees shows that female choice may be more apparent than real. Behavioral Ecology and Sociobiology , 65, 921-933.

Muller, M. N., Kahlenberg, S. M., \& Wrangham, R. W. (2009). Male aggression against females and sexual coercion in chimpanzees. In M N Muller \& R. W. Wrangham (Eds.), Sexual coercion in primates and humans: an evolutionary perspective on male aggression against females (pp. 184-217). Cambridge, MA: Harvard University Press.

Neumann, C., Duboscq, J., Dubuc, C., Ginting, A., Irwan, A. M., Agil, M., Widdi, A. Engelhardt, A. (2011). Assessing dominance hierarchies: validation and advantages of progressive evaluation with Elo-rating. Animal Behaviour, 82, 911-921.

Palagi, E., Paoli, T., \& Tarli, S. B. (2004). Reconciliation and consolation in captive bonobos (Pan paniscus). American Journal of Primatology, 62(1), 15-30.

Palombit, R. A. (2000). Infanticide and the evolution of male-female bonds in animals. In C. P. van Schaik \& C. H. Janson (Eds.), Infanticide by males and its implications (pp. 239268). Cambridge, U.K.: Cambridge University Press.

Polo, P., \& Colmenares, F. (2012). Behavioural processes in social context: female abductions, male herding and female grooming in hamadryas baboons. Behavioural Processes, 90(2), 238-245.

R Core Team. (2018). R: A language and environment for statistical computing. Vienna, Austria: R Foundation for Statistical Computing.. http://www.r-project.org/

Reddy, R., \& Mitani, J. (2020). Adolescent and young adult male chimpanzees form 
affiliative, yet aggressive, relationships with females. Journal of Human Evolution, 144, 102813.

Schaffner, C. M., \& Aureli, F. (2004). Conflict resolution. International Journal of Phytoremediation, 21(1), 295-297.

Silk, J. B. (1996). Why do primates reconcile? Evolutionary Anthropology, 5(2), 39-42.

Silk, J. B. (2002). Practice random acts of aggression and senseless acts of intimidation: The logic of status contests in social groups. Evolutionary Anthropology, 11(6), 221-225.

Silk, J. B., Cheney, D. L., \& Seyfarth, R. M. (1996). The form and function of post-conflict interactions between female baboons. Animal Behaviour, 52, 259-268.

Smuts, B. B. (1985). Sex and friendship in baboons. Hawthorne, NY: Aldine Publishing.

Smuts, B. B., \& Smuts, R. W. (1993). Male aggression and sexual coercion of females in nonhuman primates and other mammals: evidence and theoretical implications. Advances in the Study of Behavior, 22, 1-63.

701

702

703

704

705

706

707

708

709

710

711

712

Swedell, L. (2015). Strategies of sex and survival in female hamadryas baboons: Through a female lens. Upper Saddle River, NJ: Pearson Prentice Hall.

Swedell, L., \& Schreier, A. (2009). Male aggression towardsfemales in hamadryas baboons: conditioning, coercion, and control. In M. N. Muller \& R. W. Wrangham (Eds.), Sexual coercion in primates and humans: an evolutionary perspective on male aggression against females (pp. 244-268). Cambridge, MA: Harvard University Press.

Swedell, L., Leedom, L., Saunders, J., Pines, M. (2014). Sexual conflict in a polygynous primate: Costs and benefits of a male-imposed mating system. Behavioral Ecology and Sociobiology, 68(2), 263-273.

Thierry, B. (2000). Covariation of conflict management patterns across macaque species. In Filippo Aureli \& F. B. M. de Waal (Eds.), Natural Conflict Resolution (pp. 106-128). Berkeley, CA: University of California Press. 
713 Thierry, B., Aureli, F., Nunn, C. L., Petit, O., Abegg, C., \& de Waal, F. B. M. (2008). A

714 comparative study of conflict resolution in macaques: Insights into the nature of trait 715 covariation. Animal Behaviour, 75(3), 847-860.

716 Webb, C. E., Baniel, A., Cowlishaw, G., \& Huchard, E. (2019). Friend or foe: Reconciliation 717 between males and females in wild chacma baboons. Animal Behaviour, 151, 145-155.

718 Weingrill, T., Lycett, J. E., Barrett, L., Hill, R. A., \& Henzi, S. P. (2003). Male consortship 719 behaviour in chacma baboons: the role of demographic factors and female conceptive $720 \quad$ probabilities. Behaviour, 140, 405-427.

721 Weingrill, T., Lycett, J. E., \& Henzi, S. P. (2000). Consortship and mating success in chacma baboons (Papio cynocephalus ursinus). Ethology, 106(11), 1033-1044.

723 Wittig, R. M., Crockford, C., Wikberg, E., Seyfarth, R. M., \& Cheney, D. L. (2007). Kinmediated reconciliation substitutes for direct reconciliation in female baboons. Proceedings of the Royal Society B: Biological Sciences, 274(1613), 1109-1115. 
Table 1. Summary of the main proximate and ultimate hypotheses proposed to explain postconflict affiliative behaviour.

Hypothesis

Explanation

Evidence

(reviewed in Aureli et al. 2002; Arnold et al. 2010)

Proximate

Ultimate

Valuable relationships

(de Waal \& Aureli, 1997;

Kappeler \& van Schaik, 1992)

\section{Uncertainty reduction}

(Aureli \& van Schaik, 1991)

\section{Integrated}

(Aureli, 1997)

\section{Benign intent \\ (Silk, 1996)}

\section{Submissive \\ (this study)}

\section{Usually not clarified}

Motivation to reduce stress/anxiety due to uncertainty about the social situation

Motivation to reduce stress/anxiety due to uncertainty about the social situation

Signal friendly intentions (that the conflict has ended) in order to restore tolerance

Victims: fear and/or stress/anxiety about conflict escalation

Aggressors: motivation to obtain immediate social/sexual benefits, restore tolerance

\section{Repair valuable (i.e. fitness enhancing) social bond}

Reduce risk of renewed aggression, alleviate more subtle social risks, prevent negative consequences of chronic stress

Repair valuable social bond

Achieve benefits of resumed interaction (e.g. short-term objectives like grooming or access to resources)

Victims: reduce risks of renewed aggression and costs of conflict escalation (e.g. injury) Aggressors: reap the benefits of subordination/compliance of the victim (e.g. secure grooming or

\section{Kin or close affiliates (e.g. as indexed by frequency of grooming, proximity, cooperation, agonistic support) more likely to reconcile than nonkin or nonaffiliates \\ Elevated rates of self-directed behaviour (SDB) in victims and aggressors following conflicts are decreased following reconciliation}

Aggression between opponents with more valuable bonds results in higher SDB and reconciliation rates

Grunts between female-female baboons serve as signals of friendly intent and facilitate infant handling

Present study 
727 Table 2. Rate of postconflict (PC) and baseline affiliation between males and swollen females when considering only sexual behaviour or nonsexual behaviour.

Only sexual behaviour

\begin{tabular}{|c|c|c|c|c|c|c|c|c|c|c|c|c|}
\hline \multirow[b]{2}{*}{ Fixed factor } & \multicolumn{6}{|c|}{ Only sexual behaviour } & \multicolumn{6}{|c|}{ Only nonsexual behaviour } \\
\hline & Estimate & $\mathrm{SE}$ & $\begin{array}{l}95 \% \\
\text { confidence } \\
\text { interval }\end{array}$ & LRT & $d f$ & $P$ & Estimate & SE & $\begin{array}{l}95 \% \\
\text { confidence } \\
\text { interval }\end{array}$ & LRT & $d f$ & $P$ \\
\hline Intercept & -5.60 & 0.35 & - & - & - & - & -5.9 & 0.71 & - & - & - & - \\
\hline PC observation $^{\mathrm{a}}$ & 1.29 & 0.24 & {$[0.78 ; 1.73]$} & 27.1 & 1 & $<0.001$ & 1.20 & 0.13 & {$[0.98 ; 1.39]$} & 68.3 & 1 & $<0.001$ \\
\hline Female rank & -0.20 & 0.33 & {$[-0.84 ; 0.44]$} & 0.31 & 1 & 0.580 & 0.69 & 0.97 & {$[-1.29 ; 2.99]$} & 0.49 & 1 & 0.480 \\
\hline Male rank & 1.59 & 0.44 & {$[0.8 ; 2.57]$} & 12.4 & 1 & $<0.001$ & 0.77 & 0.64 & {$[-0.53 ; 2.21]$} & 1.44 & 1 & 0.230 \\
\hline
\end{tabular}

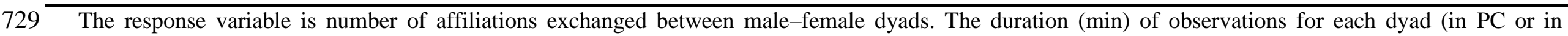

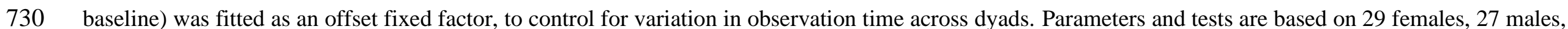

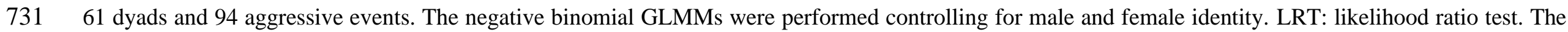

$73295 \%$ confidence intervals that do not cross zero and $P$ values of statistically significant results are highlighted in bold.

$733{ }^{a}$ Reference category: baseline. 
Table 3. Determinants of the occurrence of postconflict (PC) affiliation between males and swollen females.

\begin{tabular}{llcccccc} 
Fixed factor & Level & Estimate & SE & $\begin{array}{c}95 \% \\
\text { confidence } \\
\text { interval }\end{array}$ & LRT & $d f$ & $P$ \\
\hline Intercept & & -1.73 & 0.85 & - & - & - & - \\
Mate-guarding status & Mate guarded & 1.55 & 0.63 & {$[\mathbf{0 . 4 6 ; 3 . 8 2}]$} & 7.48 & 1 & $\mathbf{0 . 0 0 6}$ \\
Baseline rate of affiliation & & 14.85 & 11.7 & {$[-9.75 ; 53.98]$} & 1.6 & 1 & 0.206 \\
Female rank & & -0.37 & 0.84 & {$[-2.49 ; 1.47]$} & 0.2 & 1 & 0.653 \\
Male rank & & 0.47 & 0.81 & {$[-1.54 ; 2.78]$} & 0.34 & 1 & 0.563 \\
Type of aggression & CH (ref: AT) & 0.85 & 0.68 & {$[-0.47 ; 2.83]$} & 3.74 & 2 & 0.154 \\
& TH (ref: AT) & -0.46 & 0.96 & {$[-4.42 ; 1.65]$} & & & \\
\hline
\end{tabular}

735 The response variable is the occurrence of PC affiliation between males and swollen females (yes/no). Parameters and tests are based on 28 females, 27 males, and 91 aggressive events (including 43 followed by PC affiliation). Of these aggressive events 53 involved unguarded swollen females, and 38 involved mate-guarded swollen females. For this model, we removed three observed aggressive events where mate-guarded females received aggression from a nonconsort male. The baseline rate of affiliation of the dyad was calculated using focal observations collected when the female was swollen and outside an aggressive context. Type of aggression refers to attack ('AT', $N=18$ ), chase (' $\mathrm{CH}$ ', $N=58$ ), or threat (' $\mathrm{TH}$ ', $N=15$ ). The binomial GLMM was performed 
Figure 1. Pattern of postconflict (PC) affiliation between males and females. (a) Mean rate of affiliation between swollen females and males in

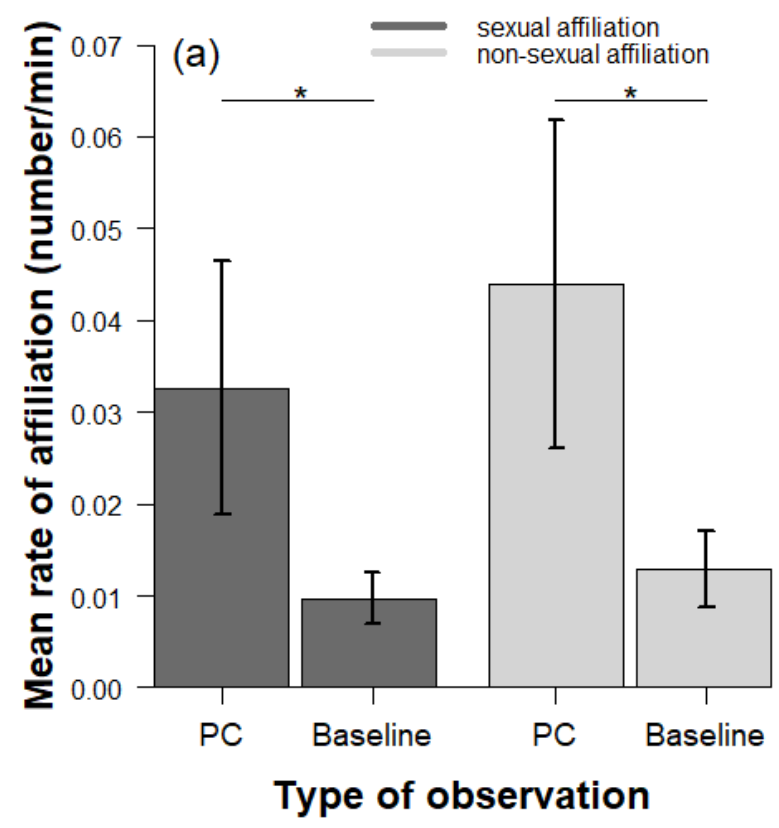

Type of observation

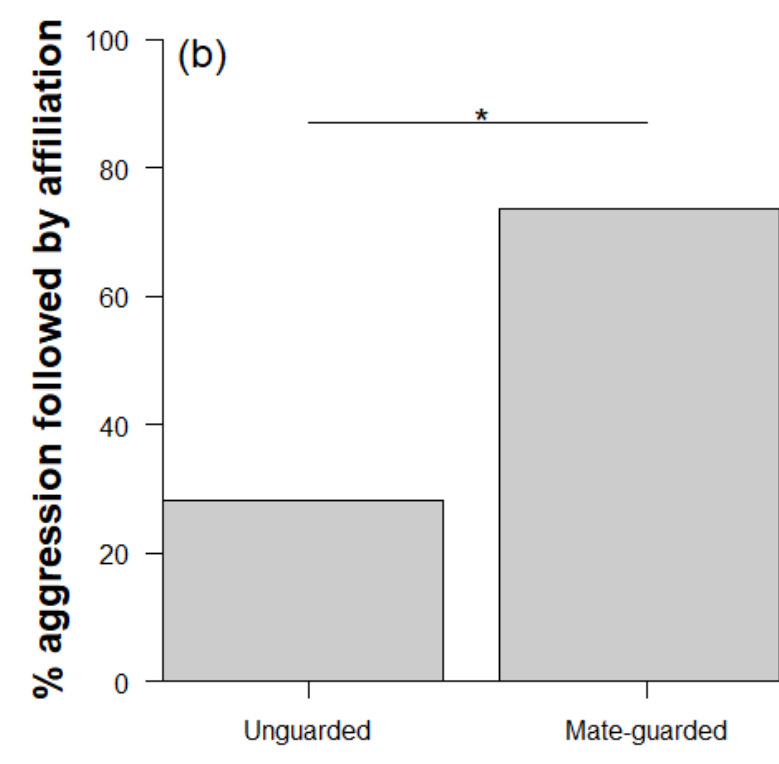

Female mate-guarding status 
747 Figure 2. Pattern of initiation of the first postconflict (PC) act and the first sexual PC act by females and males. (a) Percentage of the first PC 748 affiliative act (both sexual and nonsexual behaviour combined) of the PC sequence (lasting 15 min) initiated by females and males. (b)

749 Percentage of the first sexual PC affiliative act of the PC sequence initiated by females and males. $* P<0.05$.
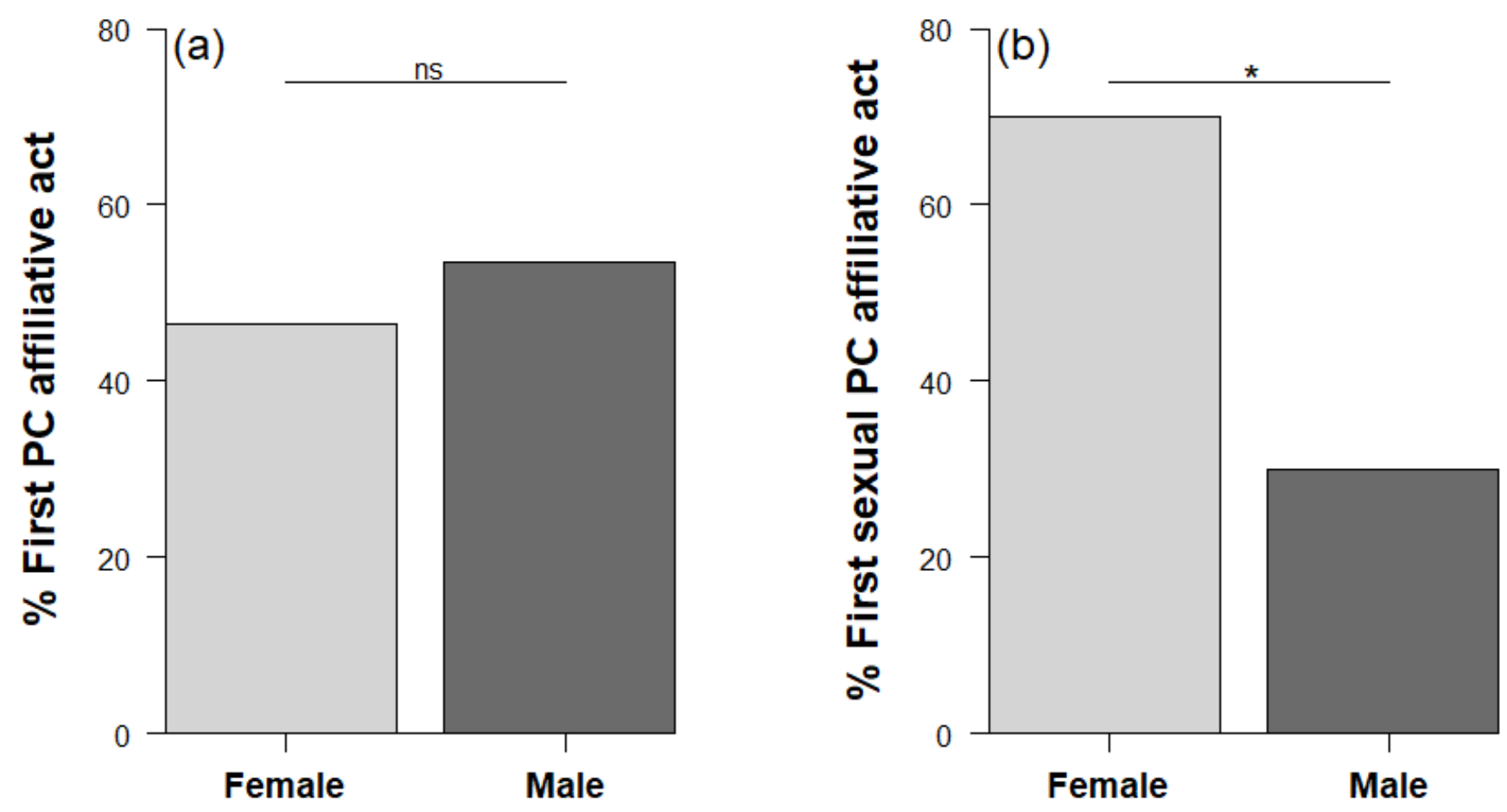


\section{Appendix 1}

752 Individual dominance ranks were assessed through focal and ad libitum observations of

753 approach-avoid interactions (supplants, when one animal actively displaces another to take

754 its place; displacements, when one animal passes close to another and makes it move away)

755 and agonistic interactions (attacks, any agonistic physical contacts including hits, bites or

756 grabbing movements; chases, when one animal chases another for a distance of at least $3 \mathrm{~m}$;

757 and threats, including staring, head bobbing and ground sweeping while oriented towards the

758 targeted individual). Female dominance hierarchies were calculated separately in each year

759 using Matman 1.1.4 (Noldus Information Technology, Wageninegen, The Netherlands) and

760 were always linear $\left(N_{2005}=412\right.$ interactions, $N_{2006}=576, N_{2013}=367, N_{2014}=1259$ in group

761 L; $N_{2005}=184, N_{2006}=460, N_{2013}=590, N_{2014}=978$ in group J, Landau's linearity index $h$ :

$762 P<0.05$ in all cases). In the analyses, we used relative female rank to control for variation in

763 group size, where absolute ranks were standardized to vary between 0 and 1 using the

764 formula: 1-((1-r)/(1-N)), where $r$ is the absolute rank of an individual (ranging from 1 to the

765 group size, $N$ ). In contrast to females, the male hierarchies were much less stable within a

766 year (Baniel et al., 2016), so male ranks were established using an Elo-rating procedure

767 implemented in the R package EloRating (version 0.43; Neumann et al., 2011). Compared to

768 matrices of dyadic interactions where ranks are calculated over a given time period, an Elo-

769 rating procedure continuously updates rankings according to the temporal sequence of

770 interactions and is better adapted to situations of unstable social dominance (Albers \& de

771 Vries, 2001; Neumann et al., 2011). This gives a score for each individual on each day of

772 observation. We derived a daily standardized rank by scaling the Elo-rating score of each

773 individual proportionally between 0 (corresponding to the minimal score and thus the lowest

774 ranking male) and 1 (corresponding to the maximal score and the highest-ranking male). 
776 Table A1. Determinents of the occurrence of postconflict (PC) affiliation between males and swollen females.

\begin{tabular}{llllccccc} 
Fixed factor & Level & Estimate & SE & \multicolumn{2}{c}{$\begin{array}{l}\text { in confidence } \\
\text { interval }\end{array}$} & LRT & $d f$ & $P$ \\
\hline Intercept & & -0.53 & 0.64 & - & - & - & - \\
Mate-guarding status & Mate guarded & 1.75 & 0.61 & {$[\mathbf{0 . 7 1 ; 4 . 0 3}]$} & 9.26 & 1 & $\mathbf{0 . 0 0 2}$ \\
Baseline rate of affiliation & & -10.62 & 26.67 & {$[-70.61 ; 47.62]$} & 0.16 & 1 & 0.690 \\
Female rank & & -0.65 & 0.81 & {$[-2.64 ; 1.1]$} & 0.64 & 1 & 0.424 \\
Male rank & & 0.73 & 0.8 & {$[-1.12 ; 2.66]$} & 0.84 & 1 & 0.360 \\
Type of aggression & CH (ref: AT) & 0.66 & 0.65 & {$[-0.77 ; 2.37]$} & 2.60 & 2 & 0.273 \\
& TH (ref: AT) & -0.42 & 0.91 & {$[-14.88 ; 1.73]$} & & & \\
& TH (ref: CH) & -1.08 & 0.78 & {$[-3.39 ; 0.42]$} & & & \\
\hline
\end{tabular}

The response variable is the occurrence of PC affiliation between males and swollen females (yes/no). Parameters and tests are based on 25 females, 26 males, and 80 aggressive events (including 38 followed by PC affiliation). Type of aggression refers to attack ('AT', $N=18$ ), chase (' $\mathrm{CH}$ ', $N=58$ ), or threat ('TH', $N=15$ ). The binomial GLMM was performed controlling for male and female identity. In contrast to Table 3, the baseline rate of affiliation of the dyad was calculated using focal observations collected when the female was nonswollen and outside an aggressive context. The 95\% confidence intervals that do not cross zero and $P$ values of statistically significant results are highlighted in bold. 
Table A2. Behavioural details on the first affiliative act and the first sexual affiliative act.

784

\begin{tabular}{llllll} 
& \multicolumn{2}{l}{ First affiliative act } & & \multicolumn{2}{l}{ First sexual act } \\
\cline { 2 - 3 } \cline { 5 - 6 } Behaviour & $\begin{array}{l}\text { Female } \\
\text { initiates }\end{array}$ & $\begin{array}{l}\text { Male } \\
\text { initiates }\end{array}$ & & $\begin{array}{l}\text { Female } \\
\text { initiates }\end{array}$ & $\begin{array}{l}\text { Male } \\
\text { initiates }\end{array}$ \\
\hline Copulation & 2 & 8 & & $2^{\text {a }}$ & $9^{\text {a }}$ \\
Presenting & 11 & NA & & 19 & NA \\
Grooming & 5 & 3 & & \\
Grunt & 0 & 6 & & & \\
Lip-smack & 0 & 4 & & \\
Sniffing perineum & 0 & 2 & & \\
Sniffing mouth & 1 & 0 & & & \\
Come-here face & 1 & 0 & & & \\
Total & 20 & 23 & & & \\
\hline
\end{tabular}

785 NA: not applicable. The table shows the type and direction of the first postconflict (PC) affiliation act and the first sexual PC affiliation act of a PC sequence 786 (lasting $15 \mathrm{~min}$ in total) between males and swollen females. There were $43 \mathrm{PC}$ sequences containing at least one PC affiliative act and $32 \mathrm{PC}$ sequences 787 containing at least one sexual act.

788 aTwo copulations had unknown initiator and are not reported here. 
Fig. A1. Occurrence of postconflict (PC) affiliation according to the baseline rate of affiliation (i.e. outside an aggressive context) of the

790 maleefemale dyad calculated over the (a) swollen or (b) nonswollen period. The violin plots (created using geom_violin from the ggplot 2

791 package, cran.r-project.org/package=ggplot2) show the kernel probability density of the data at different y values.
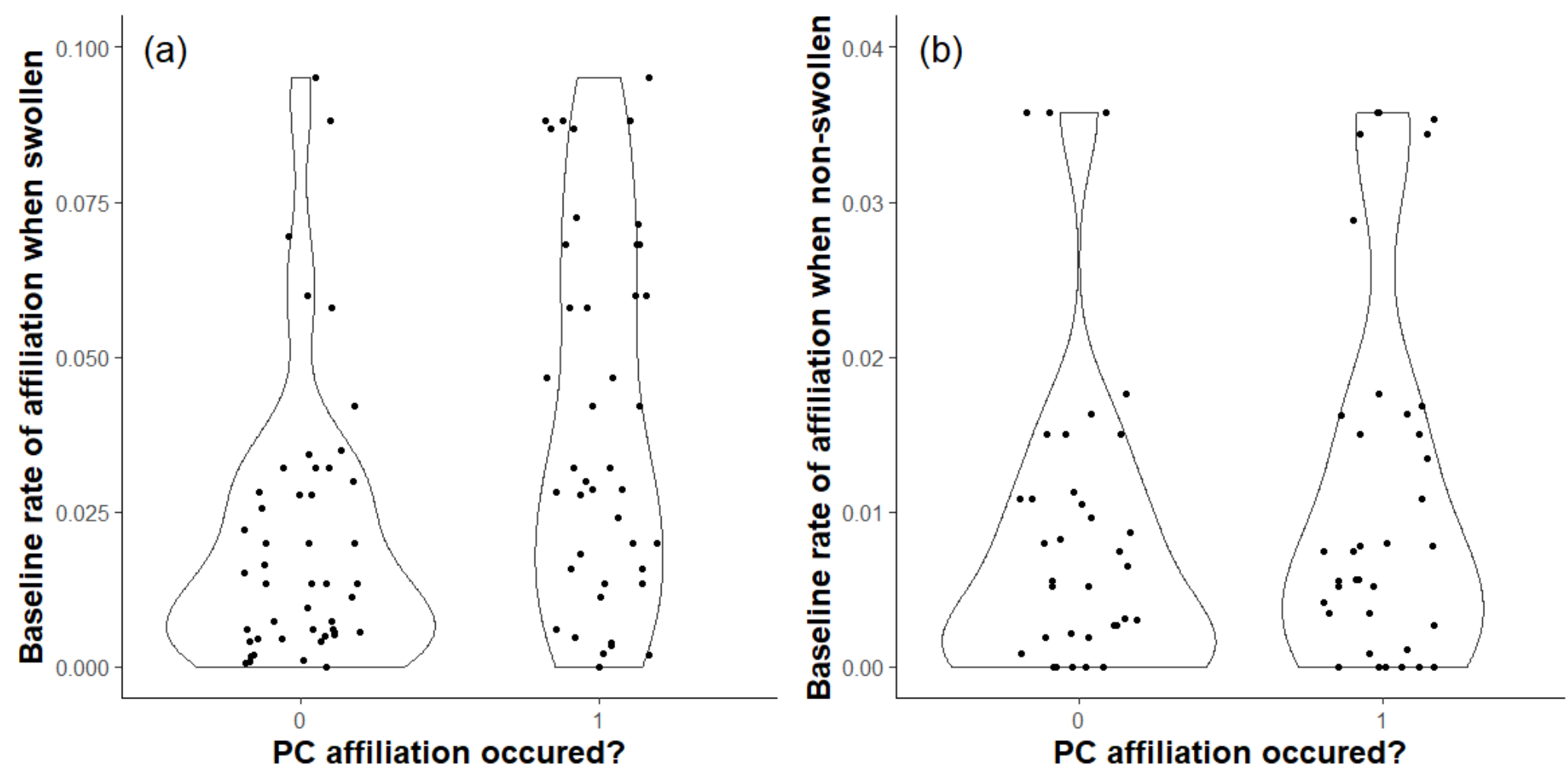